\title{
O CAIPIRA SOB O OLHAR DA ELITE PAULISTANA DAS PRIMEIRAS DÉCADAS DO SÉCULO XX
}

\author{
Hélcius Batista Pereira \\ helcius@usp.br
}

REsumo: O presente texto tem por objetivo investigar como a elite paulistana do final do século XIX até I930 avaliava o "caipira". Para tanto, trabalhamos com textos escritos por Valdomiro Silveira e Monteiro Lobato. Com base na diferença entre estas duas visões e em fatos da história social de São Paulo, identificamos uma certa ambiguidade em relação ao "caipira”, o que reflete o fato de a cidade de São Paulo e sua elite ainda estarem a meio caminho entre o rural e o urbano.

Palavras-chave: Caipira; Elite, Rural; Urbano; Valdomiro Silveira; Monteiro Lobato; Bourdieu

\section{0 . INTRODUÇÃo}

A partir principalmente de I870, a cidade de São Paulo iniciou um processo de crescimento econômico significativo. Com construção das ferrovias, a cidade ampliou o seu papel histórico de entreposto comercial e, a partir daí, passa a concentrar capitais que permitem o desenvolvimento de seu comércio, de seu nascente setor bancário e a instalação das suas

I Doutor em Filologia e Língua Portuguesa -FFLCH/USP. 
primeiras fábricas. Nas primeiras décadas do século $\mathrm{xx}$, esse processo continuou, permitindo o surgimento das primeiras instalações fabris produtivas que utilizavam energia elétrica, cuja implantação na cidade se fez graças à atuação da The São Paulo Light and Power Company Limited. O setor industrial passou por um processo de concentração, com a criação de estabelecimentos de grande porte que empregavam muitos funcionários, dentre os quais podemos citar a Companbia Nacional de Tecidos e Juta, com I.50o funcionários; a F. Matarazzo E Cia - Fábrica Mariângela, com 450 empregados; a Clark Ltda, com 300 funcionários; a Regoli e Crespi, com 610. O "Triângulo" (formado pela rua xv de Novembro, rua Direita e rua São Bento) concentrava lojas de comércio de luxo, como a Casa Clark, a Ao Preço Fixo, a Casa Fretin, a Ao Mundo Elegante, a Mappin E Webb e sua concorrente, a Casa Alemã. O setor bancário também se diversificou, de modo que, ao lado de bancos nacionais, surgiram novos bancos estrangeiros, dentre eles Banca Francese e Italiana per l'America del Sud e o London E' River Plate Bank. Além disso, o mercado imobiliário expandiu-se largamente, movimentando a construção civil, com destaque para a Companbia City que passou a atuar na venda de terrenos na Vila América, Butantã, Lapa, Pacaembu, Alto de Pinheiros, e Jardim América, além de explorar a própria Avenida Paulista, aberta nos anos i89o (SAes, 2004: 23I).

$\mathrm{Na}$ década de 1920 , muitos investimentos passaram a se dar na fabricação de bens duráveis. Assim, surgiram a Companbia Brasileira de Cimento Portland, em Perus, a Fábrica de Aço Paulista, na Mooca, e a Companbia Brasileira de Mineração e Metalurgia, esta última de Alexandre Siciliano. Também data da década de 1920 a chegada das grandes empresas automobilísticas à cidade de São Paulo, como a Ford (1919) e a GM $(\mathrm{I} 924)^{2}$, em unidades que operavam para a montagem de veículos. $\mathrm{Na}$ área comercial, houve um aumento expressivo de empresas atuantes: de 4.905

2 A GM em I926 se transferiu para São Caetano. 
empresas existentes em I9I4, atingiu-se o número de II.682 em I929. Já o sistema bancário agregou novas instituições, como о BANESPA (resultado da encampação pelo governo do estado do Banco de Crédito Hipotecário e Agrícola), o Banco Noroeste do Estado de São Paulo, o Banco Português do Brasil, entre outros.

Do ponto de vista populacional, a cidade também assistiu a um crescimento significativo. Segundo Marcílio (2004), São Paulo dobrou sua população de 1872 a I89o, quando atingiu 64,9 mil habitantes. E o crescimento continuou vertiginoso nas primeiras décadas do século xx: atingiu-se um total de 239,8 mil habitantes em I900, 579 mil em r920 e I milhão e 300 mil em 1940. Um dos elementos fundamentais para essa explosão populacional foi a chegada dos imigrantes, muitos deles atraídos para o trabalho nas lavouras de café, e que acabaram em grande medida se fixando nas áreas urbanas. Assim, a imigração, a partir principalmente da década de I880, começou a pesar sobre o tamanho e o perfil da população de São Paulo. De I880 a I889, cerca de 137,3 mil italianos, I8,4 mil portugueses, 4, 8 mil espanhóis e mais 6 mil outros estrangeiros chegaram à Província de São Paulo, de acordo com dados da Secretaria da Agricultura do Estado de São Paulo (Freitas, 2006: 4I). Desse modo, em I893 cerca de 54,6\% da população paulistana era estrangeira (HALL, 2004: I2I).

E nesse processo em que a cidade se afastava cada vez mais da configuração que teve na maior parte do período colonial, quando ainda era um pequeno e pacato núcleo mais propriamente rural que urbano, como sua elite passou a avaliar o "caipira"? Atraída pelas inovações que implantava ou que "importava”, principalmente da Europa, passou abruptamente a repudiá-lo? Ou ainda manteve com ele laços que só lentamente foram superados? Estas são as questões que procuraremos responder neste artigo a partir da análise de textos produzidos para a elite, razão pela qual, acreditamos estarem impregnados de suas visões e de suas crenças sobre o tema. 


\section{Pressupostos teóricos}

Para a realização deste trabalho, partimos da proposta de Pierre Bourdieu, que define habitus como

[...] um sistema de disposiçôes duráveis e transponiveis que, integrando todas as experiências passadas, funciona a cada momento como matriz de percepçôes, de apreciaçôes e de ações - e torna possível a realização de tarefas infinitamente diferenciadas, graças às transferências analógicas de esquemas, que permitem resolver os problemas da mesma forma, e às correçôes incessantes dos resultados obtidos, dialeticamente produzidos por esses resultados" (BouRdieu, I994: 65).

O habitus assim concebido é um sistema socialmente constituído, resultante do acúmulo das experiências passadas, e que foi interiorizado pelo indivíduo, para, a partir daí, funcionar como estruturador das ações individuais. Esse processo de interiorização é individual, mas não está restrito ao domínio da individualidade. "A relativa homogeneidade dos habitus subjetivos (de classe, de grupo) encontra-se assegurada à medida que os individuos internalizam as representaçôes objetivas segundo as posiçôes individuais que efetivamente desfrutam" (ORTIZ, 1994: 19). O depósito do habitus no indivíduo se dá através das instituições de socialização da qual participa desde os primeiros momentos de sua vida (ou seja, sua família, sua escola, etc).

Para Bourdieu, esse processo de interiorização faz com que a História seja vertida em natureza. Por isso, para o indivíduo não haverá uma clareza de que se trata de algo definido historicamente: é resultante de um processo de "esquecimento da História que a própria História produz" (Bourdieu, 1994: 65).

Mas, como o babitus atua para direcionar as práticas do indivíduo? De forma inconsciente ou "quase consciente", por meio do habitus, o indivíduo antecipa o valor e o significado que o seu ato pode ganhar, antes 
de partir para a sua execução. Com isso, esse dispositivo atua de forma decisiva para a definição daquilo que será produzido ou executado, já que foi filtrado por essa matriz de valoração, de apreciações e de sanções dos atos práticos.

Voltando à definição do conceito de habitus dada por Bourdieu (1994), percebemos a menção de que este tem caráter "durável”, o que revela sua tendência conservadora. À medida que oferece uma "matriz de apreciações" resultante da experiência passada, prevendo censuras e prestígios, silenciando ou moldando os discursos, o habitus colabora para a conservação das estruturas sociais que o produziram.

Por outro lado, Bourdieu associa ao babitus o adjetivo "transponível", indicando que pode ser transposto. Ou seja, sua tendência conservadora não lhe dá um caráter de categoria imutável ou estática. Assim, ele “...é durável mas não estático ou eterno: as disposições são socialmente montadas e podem ser corroídas, contrariadas, ou mesmo desmanteladas pela exposição a novas forças externas..." (WACQUANT, sem data: 3 ).

É preciso perceber que o habitus não gera mecanicamente ações e que estas não são facilmente dedutíveis das estruturas sociais (das condições objetivas) que o originaram. A relação não é imediata, o que implica que o habitus não é um sistema que torna previsíveis as ações individuais. Isso porque o habitus é

[...] um produto dos condicionamentos que tende a reproduzir a lógica objectiva dos condicionamentos, mas fazendo-a sofrer uma transformação; é uma espécie de máquina transformadora que faz com que 'reproduzamos' as condições sociais da nossa própria produção, mas de uma maneira relativamente imprevisivel, de uma maneira tal que não podemos passar simples e mecanicamente do conbecimento das condiçães de produção ao conhecimento dos produtos (BouRdieu, 2003: I40). 
Como não gera mecanicamente as ações, o conceito de habitus não mantém qualquer relação com as noções behavioristas que concebem o desenvolvimento do conhecimento como resultante da imitação e repetição de atos. Aliás, Bourdieu justifica sua escolha lexical pelo termo em latim porque esse ressaltaria a sua capacidade criativa e geradora, que a palavra "hábito" não contém (Bourdieu, I994: 6I).

Essa imprevisibilidade ocorre porque o modelo prevê que o indivíduo faça ajustamentos diante da situação que enfrenta, na tentativa de se adaptar a esta. Tais ajustamentos "...podem determinar transformaçôes duradouras do habitus, mas que permanecem dentro de certos limites" (BourDIEU, 2003: I4I).

Partindo dessa conceituação bourdieuniana, acreditamos que os produtos linguísticos, ainda que resultantes da produção individual, carregam as marcas do habitus do grupo social de seu produtor. Se isso é verdade, é possível analisar tais discursos individuais e, a partir deles, identificar, mesmo que de forma não absoluta e não mecânica, certos elementos dessa matriz de apreciação e de julgamentos, ou seja, do habitus, do grupo social a que pertence. Isso é o que proporemos na próxima seção, onde explicitaremos a metodologia que utilizaremos para identificar qual a avaliação que a elite paulistana fazia da população dita "caipira".

\section{Metodologia}

Para avaliar o habitus da elite paulistana no que diz respeito aos seus julgamentos em relação ao caipira, nós procuramos constituir corpus de análise com textos de autores que tinham como público-alvo membros da elite paulistana. Assim chegamos aos textos produzidos por dois autores que tomam o caipira como temática: Valdomiro Silveira e Monteiro Lobato. 
Valdomiro Silveira, desde o fim do século xIx, passou a publicar em vários jornais da época alguns contos que colocavam o caipira como figura central. Só mais tarde, na década de 1920 , estes mesmos textos, publicados esparsamente na imprensa, foram reunidos em livro, mais precisamente em Os Caboclos. Nascido em Bom Jesus da Cachoeirinha, na parte paulista do Vale do Paraíba, em I873, o autor viveu parte da infância na capital e, em seguida, mudou-se para Casa Branca, pequena cidade do interior. Com dezessete anos, mudou-se novamente para a capital estudando no Seminário Episcopal, no curso anexo à Faculdade de Direito, formando-se em Ciências Jurídicas e Sociais. Em seguida, foi nomeado promotor público em Santa Cruz do Rio Pardo, retornando depois para Casa Branca. Voltou a residir em São Paulo, onde se casou com uma paulistana, mudando-se finalmente para Santos, para fixar residência, a partir de 1905. Essas idas e vindas, do interior para a capital do estado, certamente colaboraram para desenvolver a sua percepção sobre os diferentes dialetos paulistas, o que foi registrado em sua produção literária.

No presente trabalho, analisaremos os textos que publicou no ano de I906 em O Estado de São Paulo: "As Fruitas", "Mau Costume", "Tal e Qual", "Eu, no Sertão", "A Trama”, "A Avinha Mâ", "A Pantasma", "No Sertão" e, finalmente, "Enredos".

O outro autor que forneceu textos para a constituição do nosso corpus foi Monteiro Lobato. Nascido em Taubaté em i882, Lobato estudou na Faculdade de Direito do Largo São Francisco, assim como Valdomiro Silveira. Após sua formatura, tornou-se promotor público em Areias, no Vale do Paraíba. Abandonou a promotoria após receber por herança de seus avós uma propriedade rural, tornando-se fazendeiro e produtor de café. Mas endividado, vendeu sua propriedade em i917. A partir daí, envolveu-se com investimentos na área editorial, tornando-se proprietário da Revista do Brasil e fundando a Editora Monteiro Lobato. No final da década de 20, tornou-se adido comercial do Brasil nos Estados Unidos. $\mathrm{Na}$ década de 30, passou a se envolver com investimentos petrolíferos no 
Brasil, fundando a Companhia Petróleos do Brasil. Faleceu em São Paulo em 1948.

De Monteiro Lobato, analisaremos dois artigos constantes do livro Urupês, publicado pela primeira vez em igr8: "Velha Praga" e "Urupês". Assim como os contos de Silveira que selecionamos, tais textos haviam sido publicados anteriormente, em I9I4, no jornal da família Mesquita.

\section{Evidências nos textos de Valdomiro Silveira e Monteiro LOBATO}

\subsection{O caipira em Valdomiro Silveira}

Em pesquisa que fizemos no Arquivo Público do Estado de São Paulo, chamou-nos a atenção o fato de, em I906, os textos de Valdomiro Silveira terem sido publicados no jornal O Estado de São Paulo, com frequência e quase sempre, em posição de destaque - em primeira página ${ }^{3}$. Suas narrativas tinham por objetivo aprofundar-se no universo rural e caipira, mediante o uso de uma linguagem que procurava representar o dialeto caipira.

Do contato profundo que teve com a cultura rural e paulista tradicional, Silveira coletou matéria-prima para sua literatura que, em muito, se diferencia da de seus contemporâneos pelo tratamento valorativo que dava ao caipira, à sua linguagem e à sua cultura. É o que podemos comprovar nos 7 textos que extraímos de O Estado de S. Paulo.

Em "As Fruitas", a linguagem do narrador pauta-se pela norma culta, mas os personagens se comunicam por meio do dialeto caipira (ainda que

3 A primeira página dos jornais do início do século não tinha, como hoje, a função de destacar os assuntos mais importantes, mas não deixava de dar maior visibilidade aos textos ali publicados. 
simulado ou mimetizado), sem que isso os ridicularize ou seja instrumento para produzir riso no leitor:

“- Arre! tio Ignacio! Vassuncê mandou que nós viesse' às dez horas, nós aqui estemo’, e vassuncê nem se mexe!!

- Tio Ignacio, nunca pensei que mecê inda não tivesse acordado!" (Silveira, oI/o8/1906: I).

No trecho acima, é preciso notar não somente o uso dos pronomes de tratamento "vassuncê" e "mecê", mas também o paradigma de concordância verbal utilizado em "nós viesse" e "estemo", ambos associados ao dialeto caipira.

Em "Mau Costume", a representação do dialeto caipira está não somente na fala dos personagens, mas na linguagem do narrador-personagem que conta sua aventura amorosa com Tuca:

Quando truxe a Tuca p'ra morar comigo (você na certeza se alembra), a mo que vinha trazendo uma riqueza: eu 'tava alegre por demais. Meu picaşo comia a estrada tão ligeiro e tão esperto e muitas vez, a Tuca, que trazia as mãos trançadas no meu corpo, chegou a pedir que eu segurasse um tiquinho a rédea, porque ella quaji que perdia o folgo em tamanha correria (SILVeIRA, I7/II/Igo6: I).

Para Leite (1992), Valdomiro Silveira trabalhava não puramente com o registro do que é ordinário, superficial e pitoresco no universo caipira, mas também lança mão de processos de estilização. É o que conseguiu com o tratamento que deu à linguagem, buscando a mescla da linguagem caipira e da expressão culta do narrador, minimizando ou reduzindo as oposições entre dois polos em termos de estigma. Silveira "[...] deixa entrever uma forte identificação e solidariedade com relação ao caipira, abordado como um igual sem, entretanto, desconsiderarem-se as particularidades que o caracterizam" (LeITE, 1992: 279). 
Essa busca do registro valorizado da linguagem e do universo cultural caipira diferencia Valdomiro Silveira de escritores como Cornélio Pires e Monteiro Lobato, que muitas vezes exploraram tais elementos para causar o riso de leitores citadinos ou ainda mostrar o caráter atrasado das populações do "sertão". Bernardo Élis (I974) aponta que o caminho de Silveira foi, por isso, bem mais áspero que os de seus contemporâneos, que, por isso mesmo, ficaram mais conhecidos. "Seus contos, pela estrutura, pelo ritmo, pelo tipo de construção frasal, pelas palavras, expressóes, espirito e estilo, são elaborados e construídos com observância cuidadosa da estrutura de pensamento e de cultura do homem regional-rural, ou seja, do caipira" (ÉLIs, I974: xv).

$\mathrm{Na}$ interpretação de Leite (1992), Silveira optou por trabalhar sob a perspectiva "universalizante", abordando temas genéricos (amor, violência, morte), enraizados na paisagem física e cultural do caipira. O contista trabalha com o amálgama do regional com o universal, do popular com o culto, mitificando o caipira, e a ele associando uma pureza elementar.

Em “Eu, no Sertão", identificamos bem esse recurso. O conto é narrado em primeira pessoa por um não caipira que retorna à cidade de São Paulo, amargurado pela saudade da amada que deixava no interior. No meio do caminho, atento à paisagem do campo, altamente valorizada pelo narrador em sua descrição, topa com uma roda de "fandango" e de "moda de amor". É, então, descrita a profunda impressão que a música lhe causa, trazendo à tona um sentimento de brasilidade, de amor a uma cultura que se poderia perder:

"Eu, do meu esconderijo, ou-via e annotava tudo, de apaixonado que já era por estas coisas de nossa terra, flagrantemente características e dolorosamente transitórias, pela invasão desordenada das raças" (SiLveirA, 28/o6/I9o6: I) ${ }^{4}$.

4 Note-se, nesse trecho, a menção clara às transformações sociais e culturais sentidas na época com a chegada maciça dos imigrantes. 
Em "Trama”, um caipira é enganado por um cigano em negócio de troca de cavalos. Inicialmente, a oferta do cigano envolvia, além da troca dos animais, o pagamento por parte do outro. Diante da recusa do caipira em levar adiante a negociação nessas condições, a troca de um animal por outro é proposta pelo cigano mediante um "abraço". Poderíamos aqui imaginar que o conto trabalha com a ingenuidade do caipira diante de um elemento citadino que engana o seu cliente da roça. Entretanto, o próprio cigano é também um caipira, o que fica claro pela linguagem que o autor usa para a representação de suas falas, uma das quais podemos ver abaixo:

“- Ora, ganjão, vancê não vê que meu matungo é de estampa, é fermoso, épasseiro? Antão não volta um nada, ao menos cinco notas p'ra mim beber uma garrafa de mulatinha na saida do arraial? (SILVEIRA, 3I/o7/I906: I)"

Como é possível notar, algumas marcas linguísticas da fala do cigano o igualam a seu interlocutor, como o uso do pronome "vancê", suas escolhas lexicais como "fermoso" e "antão", e o uso que faz do pronome "mim", sujeito do verbo "beber". Ou seja, como se pode ver, trata-se de um "duelo" de iguais, já que ambos pertencem ao mesmo universo rural, embora o cigano mantenha a mobilidade espacial que o caracteriza. Ao final, o caipira obtém ainda sua redenção, disparando contra o animal que, ao relinchar, parecia rir de sua condição de trapaceado.

O conto "Avinha mâ" tem por tema a morte e a saudade. A personagem Jerônyma perde seu marido e passa a sofrer muito, principalmente quando ouve o piar de uma ave chamada "sem-fim", que lhe aumentava a tristeza e a saudade do esposo falecido. Ela chama o "tomador de conta do sítio", e pede a este seu empregado que lhe prepare uma arma para que ela mesma matasse o pássaro. Após dar fim à ave, Jerônyma descobriu no dia seguinte outro piar da "sem-fim", percebendo que "saudade não se mata: ou ella morre por si, ou acaba num dia por matar a gente aos poucos" (Silveira, io/o8/I906: I). 
O mesmo tema da saudade aparece em "A Pantasma". Novamente, o conto trabalha com a valorização do saber do caipira em face de questão universal e nobre, utilizando-se, desta vez, de um narrador que simula o dialeto caipira, como podemos ver no pequeno trecho abaixo :

'Quem nos dirá que sa Minervina não apparece p'r' elle só porque tá sentindo sodade, lá nesses mundos de Deus? Ora, a sodade, você bem sabe, doe mais tempo e mais fundo..." (Silveira, 25/08/1906: I).

Em "Enredos", novamente a perspectiva do narrador é a do caipira. Como tema, está a sua mágoa pela nhá Maruca que, dando ouvidos às calúnias, deixa de com ele flertar, passando a ignorá-lo. Novamente o autor busca um tema universal, o amor e a rejeição, tratado sob o ponto de vista do universo do homem do campo e verbalizado em linguagem que mimetiza novamente o dialeto caipira.

Quando a associação do caipira com o que é atrasado e inculto se tornou difundida, Valdomiro Silveira atuou para combater essa desvalorização. Fez isso quando publicou, na década de I920, os seus escritos em livro, reunindo o que havia sido mostrado ao público esparsamente nos jornais desde o fim do século xIx. É o que mostra no depoimento abaixo:

Os Caboclos, reunindo vinte e quatro histórias de caipira. Os maiores esforços que fiz, naquela ocasião, visavam a dois fins: acabar com a mania, que então grassava entre alguns de nossos escritores, de mostrar o matuto como indivíduo apenas aproveitável em farsa ou troça; esclarecer que caboclo, na linguagem dos brasileiros, não quer dizer filbo de bugre, senão qualquer mixuango, tapiocano, mucufo ou tabaréu (MiLliet, S., 1950)5.

Para Silveira (2008), a obra de Valdomiro deve ser entendida em um contexto em que a intelectualidade paulista procurava buscar para si uma

5 Apud Leite (1992). 
representação nacional voltada para sua própria história. Essa busca, que não se resumiu às manifestações literárias, foi levada a cabo pelo Instituto Histórico e Geográfico, pelo Museu Paulista e pela Academia Paulista de Letras, os quais procuraram reinterpretar o passado paulista, valorizando em primeiro lugar o bandeirante e, como sua extensão, o caipira. São Paulo ganhava, no âmbito da representação simbólica e histórica nacional, um peso que correspondia à importância econômica que havia assumido. "[O caipira] foi matéria privilegiada para a arte, em geral, de fins de Oitocentos e das primeiras décadas do século passado" (Silveira, 2008: 55).

Um dos procedimentos de Valdomiro Silveira foi, então, o de idealizar um sertanejo que foi transformado em herói em oposição ao homem da cidade. As narrativas ainda trazem a oposição entre o passado e o presente, o primeiro marcado pelos ciclos agrícolas e o segundo pela modernidade que São Paulo e o autor vivem já nas primeiras décadas do século xx. O caipira assumiu, nesse discurso, lugar especial que guardava toda a identidade original dos paulistas, sendo "...o lugar próprio dos 'ancestrais paulistas" (Silveira, 2008: 65).

\subsection{Os caipiras em URUPÊS, DE Monteiro Lobato}

Enquanto São Paulo se tornava uma das principais cidades brasileiras, multiplicando sua população e consolidando um papel central do ponto de vista econômico, o caipira foi perdendo, no imaginário da elite republicana, os atributos positivos, deixando de assumir o papel de "símbolo regional" por excelência.

Esse discurso, de desvalorização do caipira, vai ganhando espaço em vozes com elevado poder de difusão ideológica, à medida que a cidade se agiganta e se desenvolve. Uma das visões negativas que se tornou mais popular, já no final da década de I9Io, foi a do Jeca Tatu de Monteiro Lobato. Em Urupês, publicado em 1918, o antigo fazendeiro do Vale do 
Paraíba incluiu dois artigos que mostram bem sua visão dos fatos. Em "Velha Praga", a destruição da Serra da Mantiqueira é colocada na conta dos caipiras, em uma visão elitizada dos fatos que sequer menciona a destruição das matas promovidas pelo avanço do café nas terras paulistas. Caracterizado como "parasita" e "piolho da terra", o caipira, com o seu hábito de promover queimadas, deixava as marcas de destruição na mata.

Importante mencionar que, em Lobato, o caipira tem uma raça e uma condição social específica: ele é o caboclo pobre, habitante da zona rural. Ou seja, há uma separação bem definida entre o proprietário de ter$\mathrm{ra}$ - e o próprio escritor era um - e aquele contra quem escreve, acusando de destruidor de matas virgens.

No artigo "Urupês", que dá nome ao livro, Monteiro Lobato ataca as visões romanceadas do caipira, anunciando um novo perigo: "[...] 0 caboclo é o 'Ai Jesus' nacional. É de ver o orgulho entono com que respeitáveis figurões batem no peito, exclamando com altivez: sou raça de caboclo" (LовAто, 1976: I48).

A imagem altamente negativa do caipira ainda é atribuída pelo escritor ao fato de que aquele estaria sempre alheio aos fatos históricos, diante dos quais estava "sempre de cócoras". Com ironia o autor afirma que somente ajeitado sobre os seus calcanhares é que o caipira consegue "destravar" sua língua e sua inteligência, e realizar atos simples como comer ou ingerir um café. Quando comparece à feira, é para levar coisas extraídas da natureza sem o menor esforço. A lei do menor esforço também nortearia outros aspectos de sua vida como, por exemplo, a forma como constrói sua morada, que “... faz sorrir aos bichos que moram em tocas e gargalhar ao joão-de-barro” (LовAто, I976: I48). Sua preguiça explicaria sua falta de luxo com as coisas mais simples: a mobília de sua casa, os instrumentos do cotidiano como cuias, gamelas etc.

Inculto, o caipira, segundo Lobato, vota sem saber em quem; não sabe que o presidente da república não é o imperador; e é desprovido de qualquer sentimento da pátria. Está longe do verdadeiro país: o dos 
homens da elite. "O sentimento da pátria lhe é desconhecido. Não tem sequer a noção do país em que vive" (LовATo, 1976: 152).

$\mathrm{O}$ autor também ridiculariza a "medicina" caipira. Esta seria formada por "tudo quanto mais repugnante e inócuo existe na natureza" (Lовато, 1976: I53), além de ser baseada em simpatias.

Nem na arte o caipira teria trazido qualquer contribuição para os brasileiros, o que, segundo o autor, contrastava com a arte rústica do camponês europeu, caracterizada como "opulenta". Lobato ridiculariza os mais famosos violeiros caboclos, que ficariam somente no "tempero", sem de fato produzirem algo que possa ser digno de consideração.

Monteiro Lobato é, portanto, representante - e ao mesmo tempo grande divulgador - de uma visão altamente negativa do caipira. Este não mais pode ser identificado com a figura do verdadeiro paulista, agora um membro da elite (Ferretti, 2004: I63).

Evidentemente que esta não é a única visão da cultura caipira entre os membros da elite. Mas o bom sucesso de Urupês demonstra a força da dissociação da elite paulista da sua origem rural.

\subsection{Contrapondo as visões de Valdomiro Silveira e Monteiro Lobato}

A contraposição das visões de Valdomiro Silveira e Monteiro Lobato mostra concepções aparentemente contraditórias. Enquanto o primeiro atribui ao caipira muitos traços positivos, o segundo, nos textos aqui analisados, faz deste uma avaliação extremamente negativa. Seriam estas, então, visões particulares acerca do caipira, resultantes da individualidade dos autores aqui analisados? Aqui pretendemos mostrar que não, e para provar isso devemos fazer uma pequena recriação do contexto histórico de produção das obras desses dois escritores. 
Na realidade, a qualificação de "caipira" recebia por parte da elite, na virada do século xix para o Xx, um tratamento ambíguo. Essa ambiguidade encontra explicação na relação que essa mesma elite estabelecia com o rural, ainda que residisse na cidade e buscasse o moderno e o urbano.

Em primeiro lugar, é preciso lembrar que boa parte de seus integrantes havia nascido e vivido na zona rural durante a infância e/ou parte da juventude, nas grandes fazendas de café e de cana-de-açúcar. E a mudança para a capital não implicou no rompimento abrupto com o modo de vida da fazenda ou dos pequenos núcleos urbanos em que viviam antes.

Mesmo quando passaram a residir em São Paulo, nas últimas décadas do século XIX, as famílias proprietárias de terra, durante boa parte do ano, mantiveram o hábito de se transferir para sua outra residência na zona produtora, retornando às suas fazendas e mantendo, com isso, forte laço com o rural. É o que mostra o depoimento de Maria Paes de Barros sobre sua família, que partia para suas propriedades, levando escravaria e bens (BARros, I988: 65).

A própria fixação da principal residência na cidade de São Paulo, inicialmente, apenas transplantou para a zona urbana o modo de morar da fazenda, já que a elite, em um primeiro momento, passou a residir em chácaras que permeavam a área citadina (MARcílio, 2004: 265).

Ainda que, posteriormente, a moradia tenha sido em chalés ou, ainda, em palacetes, o fato de os negócios girarem em torno do "capital cafeeiro" fazia com que houvesse a necessidade de sintonia, não somente com o exterior (com a Europa e outros mercados dos produtos agrícolas), mas também com a fazenda, no interior do estado, onde a produção se dava. Portanto, até os anos iniciais do século xx a elite paulistana ainda se encontrava entre o rural e o urbano ou, ainda, a meio caminho entre o arcaico e o moderno.

Isso explica porque, em muitos dos textos e produções voltadas para a elite da cidade de São Paulo, é possível encontrar certa ambiguidade diante do "caipira", percebida, por exemplo, por Ferreira (2002) nas pági- 
nas do Almanach Litterario de São Paulo 6 , publicado nas décadas de 1870 e i88o.

Os textos do Almanach desenham o caipira como homem ingênuo, supersticioso, crédulo, de aparência bruta e, portanto, o oposto da modernidade, do culto e do científico. Paradoxalmente, argumenta o historiador, essa imagem negativa convive com a conviç̧ão de que o caipira era a "fonte da sabedoria popular", detentor de valores que deveriam ser resgatados, afastando o materialismo e o pragmatismo da sociedade urbana.

Conforme descreve Ferreira, a representação do caipira como o homem pobre, lento e preguiçoso, anacrônico em um tempo marcado pelo progresso, já aparecia nos textos publicados no Almanach, antecipando a figura do Jeca Tatu, tão divulgada por Monteiro Lobato. Mas esse comportamento não era ainda - como seria mais tarde - relacionado à sua suposta inferioridade racial.

Analisando cartas de leitor publicadas na imprensa de São Paulo no século XIX, Oliveira e Kewitz (2009) também chegam a resultados semelhantes aos de Ferreira (2002). Os textos publicados estabelecem uma correlação entre o homem da zona rural e o caipira, associando a este o caráter de incivilizado e inculto. Nas cartas, muitas vezes o autor se autodenomina um caipira. Em uma das cartas identificadas pelas pesquisadoras, o autor se atribui uma linguagem "groceira", típica dos "homens da roça”, cujo único compromisso é com a "verdade”, explicitando um certo orgulho em se autodenominar "caipira".

Mesmo quando, no campo imagético, a elite valorizou o caipira, isso não implicou uma maior proximidade social entre ela e a camada popular rural. A elite agiu sempre visando a manter “...a discriminação estamental

6 O Almanach foi levado a cabo por obra de José Maria Lisboa, jornalista nascido em Portugal, mas que, após fixação em São Paulo, deixou-se assimilar facilmente. Continha, em verdade, textos não só de Lisboa, mas de diversos membros da "sociedade paulistana". 
que, desde a fundação do Brasil, separava cavaleiros e peões, os que eram carregados e os que carregavam, os calçados e os descalços" (MARTINs, 2004: I58).

Entretanto, aos poucos, o caipira foi perdendo, no imaginário da elite republicana, os atributos positivos, deixando de assumir o papel de "símbolo regional" por excelência. As divergências que encontramos nos textos de Valdomiro Silveira e de Monteiro Lobato refletem exatamente essa transição lenta da cidade de São Paulo e de sua elite que, ainda nas primeiras décadas do século $\mathrm{xx}$, encontrava-se no limite do rural e do urbano, do arcaico e do moderno. Como produtos linguísticos e literários criados por homens da elite e voltados para ela, esses textos refletem um momento sócio-histórico em que a cidade a mantinha, com laços firmes, atada ao campo, ao mesmo tempo em que ela pretendia ser tão urbana e moderna como a elite das maiores cidades europeias.

\section{CONCLUSÃo}

No presente texto, procuramos investigar o sistema de avaliações da elite paulistana do início do século xx, dispostas em seu habitus, no que diz respeito ao "caipira". Os textos de Valdomiro Silveira e Monteiro Lobato, que constituíram nosso corpus de análise, mostraram certa ambiguidade em relação ao caipira. Essa posição foi confirmada pela contextualização sócio-histórica, que demonstrou que a cidade de São Paulo e a elite paulistana do período estavam a meio caminho do rural e do urbano, da zona produtora agrí́cola e dos centros "civilizados" da Europa.

\section{Bibliografia}

Bourdieu, Pierre. Esboço de uma Teoria da Prática. In: Ortiz, Renato (Org.) Pierre Bourdieu: Sociologia. São Paulo: Ática. Coleção Grandes Cientistas Sociais. 1994. Volume 39 
- Questôes de Sociologia. Lisboa: Fim de Século, 2003.

. O Poder do simbólico. Rio de Janeiro: Bertrand Brasil, $200 \%$.

ÉLis, Bernardo (1974) Valdomiro Silveira. In: Silveira, Valdomiro, O mundo Caboclo de Valdomiro Silveira. Rio de Janeiro: Cultrix, 1974.

Ferretti, Danilo José Zioni. A Construção da Paulistanidade. Identidade, Historiografia e Politica em São Paulo (1856-1930). São Paulo: FrLCH/ USP, 2004. Tese de Doutorado.

Gonçalves, Júnia Silveira. Notas Bibliográficas sobre Valdomiro Silveira. In: Silveira, Valdomiro O mundo Caboclo de Valdomiro Silveira. Rio de Janeiro: Cultrix, I974.

Hall, Michael. O imigrante na cidade de São Paulo in: Porta, Paula (Org.) História da cidade de São Paulo: a cidade na primeira metade do século Xx. São Paulo: Paz e Terra, 2004. Vol. 3. pp. I2I-I5I.

Koshiyama, Alice Mitika Monteiro Lobato: intelectual, empresário, editor. São Paulo: Edusp, 2006.

Loвato, Monteiro. "A velha praga”. Urupês. São Paulo: Editora Brasiliense, $1976.20^{\mathrm{a}} \mathrm{ed}$.

. “Urupês”. Urupês. São Paulo: Editora Brasiliense, 1976. $20^{\mathrm{a}} \mathrm{ed}$.

Marcilio, Maria Luiza. A cidade de São Paulo: povoamento e população, I750-I850, com base nos registros paroquiais e nos recenseamentos antigos. São Paulo: Editora Pioneira, I973.

A população paulistana ao longo de 450 anos. In: Porta, Paula (Org.) História da cidade de São Paulo: a cidade colonial I554-I822. São Paulo: Paz e Terra. Vol. I. pp. 245-269, 2004.

Martins, José de Souza. O migrante brasileiro na São Paulo estrangeira. In: Porta, Paula (Org.) História da cidade de São Paulo: a cidade na primeira metade do século XX. São Paulo: Paz e Terra, 2004. Vol. 3. pp. $153^{-213}$. 
Ortiz, Renato. A Procura de uma Sociologia da Prática. In: Ortiz, Renato (Org.) Pierre Bourdieu: Sociologia . São Paulo: Ática, 1994. Coleção Grandes Cientistas Sociais, Volume 39.

Pereira, Hélcius Batista A realização do sujeito pela elite paulistana do inicio do século XX: uma análise em perspectiva Gerativista Trans-sistêmica. FFLCH/USP, 20IO. Tese de Doutorado.

Silveira, Valdomiro. As fruitas. O Estado de São Paulo. São Paulo, pg. I, 08/or/1906.

. Mau Costume. O Estado de São Paulo. São Paulo, pg. I, I7/or/19o6. .Tal e qual. O Estado de São Paulo. São Paulo, pg. I, 25/or/19o6. .Eu, no Sertão. O Estado de São Paulo. São Paulo, pg. I, 28/o6/19o6. . Trama. O Estado de São Paulo. São Paulo, pg. I, 31/o7/19o6. . A avinha má. O Estado de São Paulo. São Paulo, pg. I, ro/o8/19o6. . A Pantasma. O Estado de São Paulo. São Paulo, pg. I, 25/o8/19o6. . No sertão. O Estado de São Paulo. São Paulo, pg. I, ı2/og/19o6. . Enredos. O Estado de São Paulo. São Paulo, pg. I, 26/ıo/ıgo6.

Silveira, Célia Regina. O Caipira: Fonte da identidade paulista em Valdomiro Silveira. In: Ferreira, Antônio Celso \& Mahl, Marcelo Lapuente (Orgs.). Letras e Identidade: São Paulo no século XX, Capital e Interior. São Paulo: Editora Annablume, 2008. 